\title{
0 ensino de cinema e a experiência do filme-carta
}

\section{Cezar Migliorin}

\section{Resumo}

Neste artigo faço uma reflexão sobre os engajamentos na sala de aula em que a prática do cinema é central. Trabalho uma experiência específica que é o filme-carta. Para pensar o espaço pedagógico discuto as noções de emancipação (Jacques Rancière) e máquina (Félix Guattari) buscando entender o papel mesmo do cinema na educação. 0 artigo estabelece ainda um diálogo entre os filósofos franceses, Jacques Rancière e a dupla Félix Guattari e Gilles Deleuze que, apesar de bases filosóficas distintas, nos ajudam a pensar a dimensão política que trazemos para o ensino e a prática do cinema.

\section{Palavras-Chave}

Cinema. Educação. Filme-Carta. Emancipação. Máquina.
Cezar Migliorin I migliorin@gmail.com Doutor em Comunicação pela Universidade Federal do Rio de Janeiro e em Cinema pela Université Paris 3 - Sorbonne Nouvelle. Professor do Programa de Pós-graduação em Comunicação da Universidade Federal Fluminense (PPGCOM-UFF).

\section{Introdução}

0 ensino de cinema é dos mais paradoxais. Fácil seria se tivéssemos um centro organizador de estéticas e discursos ao qual os alunos deveriam se reportar. Felizmente esse centro não existe. Em alguns debates sobre o papel da universidade, este centro narrativo é entregue ao mercado com a seguinte fórmula: a universidade tem a função de analisar as demandas de mão de obra e estar em constante adaptação para suprir tais demandas. Evidentemente que esta narrativa não só é triste, no sentido Spinozista - ela baixa nossas forças de agir - como ineficiente, uma vez que trata-se de: 1) duas velocidades distintas - a da produção de conhecimento e a do mercado; 2) duas naturezas distintas de relação com 0 saber - funcionalizável, no caso do mercado e de formação ampla, no caso da universidade; sem fim objetivável, mas com a finalidade da invenção e do conhecimento.

Ao assumirmos que 0 ensino de cinema acontece ainda assim, sem uma centralidade que lhe guie, não nos separamos dos paradoxos inerentes às práticas, cujo desafio na relação ensinoaprendizagem demanda invenção. Colocado de 
outra maneira: não há ensino de cinema que também não seja em si um processo de emancipação.

Neste artigo gostaria de propor dois movimentos: um primeiro, pensando o processo mesmo de emancipação e a relação com as artes; e um segundo, descrevendo e analisando a opção do filme-carta como dispositivo pedagógico.

\section{Emancipação}

Falar em emancipação demanda a urgência de um realinhamento da noção para que não a entendamos em um processo que supõe dois sujeitos, 0 emancipado e 0 a emancipar. Emancipar não é tarefa de uma mestre que indica 0 caminho àqueles que não tem luz. Sem essa divisão, a situação de criação no ambiente educacional demanda do mestre e das propostas colocadas em prática, um gesto de abertura ao que pertence aos alunos e à multiplicidade de mundos trazidos por eles. Ou seja, antes de um lugar de hierarquia entre aquele que sabe e o que não sabe, a emancipação demanda um estado de criação e montagem entre os diversos atores envolvidos em uma produção criativo-pedagógica.

Jacques Rancière (2007) desenvolveu com precisão e radicalidade tal prática emancipatória em $O$ Mestre Ignorante. Não cabe aqui repassarmos todo seu argumento, mas retomar um princípio que nos é caro para pensar e exercer o papel da universidade e do mestre, no privilegiado ambiente educacional, onde ainda é possível tensionar as centralidades narrativas e as funcionalidades do conhecimento.

0 primeiro princípio é de uma igualdade que emancipa e que não é um telos. A igualdade não é algo que se alcançará no fim de um processo, nem está submetida à um projeto e à relações de causa e efeito. Nas palavras de Rancière (2012 p. 11) "A igualdade jamais vem após, como resultado a ser atingido. Ela deve ser colocada antes." Tal princípio é perturbador para aqueles que fazem parte de um sistema com hierarquias, notas e a frequente demanda de alunos que, como todos nós, podem, eventualmente, demandar a opressão. Entretanto, em um curso em que a criação é parte do processo, 0 difícil desafio da igualdade pode atravessar as práticas, sem que saibamos ao certo o que essa igualdade produz ou como ela se instaura. Sem falar em emancipação, Gilles Deleuze e Félix Guattari também colocariam o processo político que se forja na liberdade dos possíveis de uma produção subjetiva, separado de um telos.

Vejamos essa passagem de 0 anti-édipo sobre os novos campos de possíveis que se efetivam em um acontecimento:

A atualização de uma potencialidade revolucionária explica-se menos pelo estado de causalidade, no qual, todavia, ela está compreendida, do que pela efetividade de um corte libidinal num momento preciso, esquiza cuja única causa é o desejo, isto é, a ruptura de causalidade que força a reescrever a história no próprio real e produz esse momento estranhamento plurívoco onde tudo é possível (DELEUZE; GUATTARI, 2011, p. 501). 
Se 0 ensino de cinema pode ser atravessado pelo desejo que rompe uma causalidade e uma linha reta do mestre ao estudante, esse princípio de igualdade demandaria 0 desaparecimento do mestre? A descentralização total? Entendemos que não. A igualdade não é uma igualdade de posição do sujeito, mas uma igualdade produtiva, fruto da produção do coletivo que não existe sem 0 trabalho e a igualdade de inteligências - a possibilidade de um sujeito qualquer fazer parte e diferença na criação. ${ }^{1}$ Partir da igualdade não é, assim, dizer da indiferença entre professores e estudantes, mas partir das possibilidades inventivas do grupo que depende de um princípio de igualdade de inteligências que se atualizam nas práticas, se materializa nos filmes, e não por princípios exteriores a essas.

Um primeiro princípio da emancipação está ligado a uma ruptura da dicotomia emancipador/ emancipado forjando uma igualdade de inteligências que é também um desmonte da cena igualitária como um telos, o que é necessário para a irrupção do desejo que é o que efetivamente produz uma cena de criação não dominado por um saber que a antecede.

Quando Rancière vai para 0 campo das imagens, uma de suas explícitas formas de associar igualdade e estética; ou política - como um princípio e ação em direção a igualdade - e estética, está ligada ao modo de os discursos e narrativas se hierarquizarem. Em um recente livro de entrevistas ele conta que em seu primeiro livro, A noite dos proletários (RANCIÈRE, 1988) não fez uso de expressões como "então", "porque", "uma vez que", pois não lhe interessava estabelecer dentro do texto relações de causalidade entre enunciados. Tais relações de causalidade só podem se efetivar caso haja uma hierarquia entre esses enunciados. Ou seja, é no modo de composição e montagem de textos que 0 autor vai formular uma ideia de igualdade em que os enunciados devem partir de uma equivalência entre eles, operando por relação e aproximação. Nas palavras de Rancière (2012, p. 61): “... não é evidentemente um princípio formal de fluidez, é um princípio de escritura igualitária: suprimir a hierarquia entre os discursos que explicam e aqueles que são explicados".

A sintonia com os cinemas chamados modernos, em que 0 ensaio e os filmes-cartas aparecerão, é evidente, e pode ser resumida pelo o que Deleuze chamou de uma crise da imagem-ação. Vejamos essa passagem sobre 0 cinema de Alfred Hitchcock, personagem central nesta crise:

[...] nos filmes de Hitchcock, uma vez dada (no presente, futuro ou passado), uma ação vai ser literalmente cercada por um conjunto de relações que fazem variar o seu tema, a sua natureza, o seu objetivo, etc. ${ }^{2}$ (DELEUZE, 1983, p. 223).

Pierre Clastres em A sociedade contra o estado (2012) nos fornece diversos exemplos em que há a necessidade de um líder justamente para impedir que o Estado e a hierarquia se efetive. 0 líder passa a ter um papel esquizo e desestruturante: falar sem ninguém ouvir, por exemplo. 
Ou seja, a ação, senhora portadora de uma força irreprimível do cinema de ação é envolta por outras imagens, textos, sons e mesmo ações que impedem seus desdobramentos ótimos e fazem variar os fins. Ação aqui, para Deleuze, perdeu o privilégio e a hierarquia em relação aos outros movimentos e objetos do filme. Poderíamos aproximar os autores e formular algo como: é por um princípio de igualdade que a imagem-ação entra em crise. 0 cinema nos ajuda a entender a dimensão estética da emancipação e acaba nos servindo como um princípio de igualdade para a própria sala de aula. Uma segunda linha constituinte da emancipação está ligada, então, à possibilidade de no interior mesmo dos trabalhos que fazemos com imagens e com a organização dos enunciados, não os submetermos à causalidade exterior às aproximações, tensões e potências das próprias imagens e do contato entre elas.

Se a igualdade está ligada às possibilidades discursivas, sensíveis e visíveis, antes mesmo de haver uma organização dos poderes há uma dimensão que é estética que organiza quem pode e quem não pode organizar ou fazer parte de tais ordens. Certamente não seria excessivo pensar a sala de aula como um espaço político. Michel Foucault, Paulo Freire, Frederick Wiseman e tantos outros o fizeram. Se assim o é, mais do que um espaço dado, como parte da disciplina ou apenas como um ambiente que reproduz as modulações do capitalismo a que somos demandados na sociedade de controle, traçamos um outro caminho em que nos parece possível retirar da constituição física do espaço - a sala de aula, a universidade - qualquer essencialismo político, como se estivéssemos em um dispositivo sem escape, para pensar as cenas possíveis neste mesmo espaço.

Quando Jacotot (RANCIÈRE, 2007) encontra seus alunos nos Países Baixos, sem ter com eles uma língua em comum e, a partir disso, desenvolve seu princípio de igualdade, a igualdade ainda não está efetivada, uma vez que nos termos em que estamos trabalhando, ela não depende de uma intenção. Entretanto, para que a emancipação se efetive, é também a instituição de um espaço possível para que ela se potencialize. 0 professor que opta por um espaço de emancipação facilita 0 processo, apesar de isso não se fazer sem percalços. Felizmente, na universidade pública ainda é possível estar diante de alunos e dizer: "Eu não tenho nada a ensinar para vocês". Mas não é só a instituição que pode eventualmente resistir a um mestre que só traz como garantia a disponibilidade de dedicar seu tempo aos estudantes. São as próprias expectativas dos estudantes que são confrontadas. Pode ser complexo para muitos ter que lidar com a liberdade e com a evidência de que não há nada a aprender que não dependa 
do desejo de inventar. Difícil limite para o que acredita-se ser uma prática emancipatória que pode ser lida como autoritária, uma vez que coloca no grupo a responsabilidade do conhecimento que ali se produz.

Nessa terceira linha constituinte da emancipação, a sala de aula passa a ser 0 espaço privilegiado e para tal, a desnaturalização desse espaço como um cena de divisões de poderes é essencial. Deixemos claro um primeiro ponto do argumento que desenvolvemos: a emancipação é uma prática e não um estado acabado do sujeito. Não se emancipa o sujeito, mas se estabelecem práticas que partem da igualdade das inteligências e das potências sensíveis. É pela possibilidade de uma inteligência qualquer participar da transformação de um mundo sensível que a emancipação se efetiva.

\section{Máquina}

As formas não-metodológicas de pensar a produção de conhecimento que abordaremos aqui fazem parte da reflexão de muitos autores - Blanchot (1987), White (1987), Serres (1985), Feyerabend (2007). 0 que nos interessa então é pensar uma imbricada relação entre a sala de aula e os filmes, como se fosse possível pensar uma pedagogia-máquina em que se materializa nos filmes-máquina. 0 nome poderia ser outro, uma vez que nossa atenção é voltada para uma dimensão produtiva e criativa que vai da formação de um grupo - interessado em criar junto - aos filmes e vice-versa.
Por que falamos em máquina, para entender os arranjos, montagens e invenções em uma sala de aula atravessada pelo cinema? Uma máquina funciona e nela os atores envolvidos não tem posições estáveis, mas funcionam por acoplamentos, por associações momentâneas, ao mesmo tempo em que não existem isoladamente. Esses atores, tenderíamos a pensar em sujeitos, alunos, professores, mas, pensamos em máquinas para poder absorver um caráter heterogêneo em suas constituições; além de ser um equipamento coletivo, a máquina comporta atores de natureza e dimensões diferentes. Em uma sala de aula, um sotaque que singulariza um modo de fala é parte da mesma máquina que esquece de fazer a chamada ou que coloca no centro da sala uma câmera Sony - sendo a Sony parte da máquina. Do privado ao público, do subjetivo ao estrutural - uma máquina funciona. Uma máquina funciona em silêncio, não demanda grandes movimentos e é formada por componentes micro e macro-políticos.

\section{A máquina nos permite atuar em múltiplas} velocidades, enquanto temos um sistema de ensino em que 0 conhecimento é feito por acúmulo e passagens de nível, o que deve ser bastante eficaz em muito casos; quando se trata da criação em cinema, esse método é apenas parcialmente verdadeiro e com frequência muito frágil. A máquina não é feita por acúmulo ou passagens de etapas, mas pela possibilidade de coabitação entre experiências e conhecimentos de naturezas distintas que engajam aspectos pertencentes à singularidades individuais e macro 
estruturas institucionais - impossibilitando o isolamento de ambas.

0 estudante emancipado traz um mundo consigo - pleno de códigos - mas é capaz de forjar novos começos para si, suas pesquisas e criações. Trata-se menos da execução de um projeto de conhecimento, do que uma multiplicação de possibilidades de entradas no cinema e na criação. É nessa multiplicação de entradas que o estudante tem a possibilidade de escorregar entre os códigos. Diante de histórias e teorias fundamentais do cinema, das artes, das humanidades, das tecnologias -, o pior que pode acontecer é que o conhecimento organizado se torne um fim e não um campo de possibilidades. Nesse sentido, podemos falar de um nomadismo ou de um processo a-metodológico em que o estudante de artes escorrega entre os conhecimentos organizados que a universidade é eficaz em oferecer. A máquina assim não é um motor ou acelerador dos processos de conhecimento em direção ao saber, mas um recorte instável, conectado a outras máquinas.

Quando Rancière (2012, p. 125) explica sua opção em trabalhar com a noção de cena, que poderia se confundir com a noção de máquina, ele produz um enunciado que merece que o desdobremos: "eu construí a cena como uma pequena máquina onde podem se condensar o máximo de significados em torno da questão central que é a partilha do sensível". Primeiramente, a proximidade da noção de cena com a ideia de máquina, que aqui trabalhamos, é curiosamente expressa por Rancière. A cena para Rancière pressupõe uma "desierarquização" dos códigos colocados em relação, uma imanência na constituição dos poderes, uma copresença de distintas naturezas discursivas - do particular ao universal ao mesmo tempo em que é entendida em sua dimensão produtiva: “... uma cena é tão construída quanto identificada" (RANCIÈRE, 2012 p. 123), ou seja, trabalha no real.

Se a proximidade entre as noções é evidente, a noção de máquina nos possibilita uma primeira distância em relação à metáfora teatral, o que nos parece interessante para enfatizar o campo social mesmo, e não algo que pode ser apartado do real ou fruto de uma divisão: atores/espectadores. Mas, seguindo a colocação acima, a questão central é a partilha do sensível. A noção de partilha traz uma riqueza evidente, explicitada com 0 termo francês - partage - algo se divide, algo se compartilha. Uma partilha do sensível atua no colocar junto e separar, no encontro e no esquadrinhamento. A riqueza da noção está em incorporar 0 compartilhamento no mesmo espaço em que há a divisão e a coabitação, elementos necessários para a dominação e exercício do poder, ou das práticas policiais, nos termos de Rancière (1996). Entretanto, nos perguntamos: se a noção tem a complexidade que expusemos acima, a complexidade acentrada, produtiva e que tem a possibilidade de absorver atores de múltiplas naturezas, por que ela deve estar submetida a uma forma de análise em que o esquadrinhamento é 
fundamental? Note, a cena política para Rancière é rara e só se efetiva quando em uma situação de igualdade do logos - o que é a norma em sala de aula - se choca com a desigualdade - uma palavra de ordem, uma situação de produção de hierarquias - e daí produz-se um litígio com a explicitação da desigualdade. A formulação de Rancière é rica para nos indicar o princípio igualitário que rege toda desigualdade, mas, para tal, precisará se concentrar nos encontros de divisões explícitas - aquele que não tem a fala com o que a possui, aquele que não possui o tempo com 0 que possui. Pois, antes dessa explicitação da cena dividida, há a máquina em funcionamento e esta não permite a apreensão de cenas tão claramente divididas, uma vez que é constituída por um conjunto de inter-relações de múltiplas naturezas que antecedem uma atualização. $\mathrm{Na}$ noção de máquina, é com a complexidade das tensões entre esses múltiplos atores que devemos lidar, uma vez que não há nenhuma clareza entre fronteiras que marcam espaços de pertencimentos ou de partilhas. No nosso entender a definição de cena submetida à noção de partilha do sensível obrigatoriamente impõe uma ordem à cena que a organiza excessivamente.

Quando destacamos então que a máquina é 0 modo mesmo de funcionamento de uma turma em processo de criação, uma vez que é necessário esvaziar as centralidades, aceitar movimentos de tamanhos distintos, igualar as inteligências, enfatizar a participação tecnológica nos movimentos subjetivos e permitir acoplamentos temporários; não estamos com isso apenas dando uma grande ênfase para os processos em detrimento dos produtos. Tal distinção em uma pedagogia-maquínica carece de sentido, uma vez que 0 funcionar de uma máquina não é 0 caminho para algo, mas a incorporação das matérias que se atualizam em seu próprio funcionar. Esta pedagogia com o cinema não visa assim os filmes como objetos fim, mas filmes que podem escapar da máquina e serem vistos como objetos fim passar na TV, ser apresentado em um festival ou em um canal do Youtube -, mas, sobretudo, filmes que são um nó da própria máquina e que a ela retorna, uma vez que no ambiente pedagógico, é no retorno a ele que parte importante do conhecimento se efetiva.

\section{Ensino do cinema no Regime Estético}

Se nos distanciamos da noção de cena de Rancière, sua reflexão sobre os regimes de imagem no mundo das artes pode nos ajudar a pensar as potências e paradoxos do cinema na educação. Nos perguntamos então, como pensar o lugar do professor ligado às artes dentro do que Rancière chamou de um regime estético das artes? Quando ensinamos cinema em uma oficina ou em uma cadeira ligada à realização, somos frequentemente colocados no lugar do crítico, aquele que deve olhar e avaliar, julgar, tecer comentários. Mas, 0 que significam essas demandas se o lugar mesmo do crítico nesse regime não é mais o do crítico que compara a obra a uma norma que lhe é externa? Como intensificar a independência do filme em 
relação, justamente, às regras às quais ele poderia estar submetido? Rancière (2012, p. 120, tradução nossa) nos diz: "a critica não diz o que a obra deve ser, mas o que a obra é". Tal formulação só é possível em um regime de imagens em que as obras de arte não estão submetidas nem à ordem da comunidade e nem à necessidade de mantê-la unida, como seria uma tela representando a Pietá em uma igreja (Regime Ético), nem submetida a um Regime Representativo, organizado segundo normas de verossimilhança.

Quando o mestre/crítico diz o que a obra é, por um lado a formulação de Rancière parece dar um excesso de poder ao professor, ao crítico - é ele que diz o que a obra é. Por outro, ele não pode dizer o que a obra deveria ser, ou seja, não há uma ordem externa que lhe garanta, nem mesmo o seu lugar de crítico/ mestre. A obra assim não pode ser mais que o ponto de encontro entre mundos, um ponto de encontro com o qual podemos retomar a dimensão política quando Rancière (2012 p. 221) diz: "Mas, dizer o que é uma obra significa construir um mundo sensível ao qual a obra pertence." Há nessa formulação uma explícita instabilidade da máquina que 0 cinema coloca em movimento. Uma máquina em que os processos, as materialidades e as críticas são constituintes do mundo inventado. A proximidade entre o Regime Estético e a política, nos termos de Rancière, é assim explícita. No limite, poderíamos dizer que a arte, no Regime Estético, é rara.

Se o Regime Estético retira do crítico um lugar estável de quem comenta a obra a partir de algo que lhe é exterior - a igreja, o Estado, o rei, o belo, a representação -, ele também coloca 0 estudante em um lugar absolutamente instável e desafiador, criar não só o filme, mas as regras para que ele exista, ou como escreveu Comolli (2008, p. 169), "O imperativo de 'como filmar', central no trabalho do cineasta, coloca-se como a mais violenta necessidade: não mais como fazer o filme, mas como fazer para que haja filme".

\section{Filme-carta}

0 caminho teórico que percorremos foi tracejado em paralelo à exercícios com filmes-carta feitos tanto nas aulas práticas com estudantes na Universidade Federal Fluminense, como em cursos livres, ministrados frequentemente por professores que pouca ou nenhuma experiência têm com 0 cinema. A realização de filmes-carta não é uma resposta definitiva para todas as inquietações político-estéticas levantadas neste artigo, mas é parte do que se experimenta com operações criativas que permitem a construção de uma máquina-cinema. Se saímos de questões muito gerais para experiências localizadas é também porque é na prática da sala de aula que essas máquinas e pedagogias emancipatórias podem ser inventadas e atualizadas.

\subsection{Tecnologia e escritura cinematográfica}

Dois aspectos relativos à tecnologia do cinema devem ser destacados na realização dos filmes- 
carta: 1) a liberdade e problematização dos padrões da indústria; 2) a dimensão social das tecnologias.

Uma das dificuldades das escolas e universidades é acompanhar os padrões tecnológicos do mercado de produção e distribuição cinematográfico; o som 5.1, a imagem de 4K, por exemplo. Se eventualmente equipamentos não nos faltam, eles não existem em quantidade para turmas de mais de 30 alunos. 0 filme-carta estabelece uma relação singular com a tecnologia. Longe de ter que atender a um padrão, ele é facilmente adaptável à diferentes tecnologias. Aqui também o Regime Estético está presente. Sem a norma técnica, derivamos para a complexidade da máquina e para a necessidade dos filmes serem analisados a partir das regras internas que eles propõem e não a partir de um bem fazer, mais artesanal, se quisermos, em que facilmente conseguimos organizar as hierarquias entre 0 que é 0 bom e 0 mau roteiro, a boa e a má fotografia. Assim como uma carta pode ser escrita em um guardanapo, sem com isso perder qualquer valor, a escolha de uma tecnologia se faz essencial neste trabalho.

Se nas universidades as câmeras DSLR hoje são o padrão e colocadas na lista de equipamentos a serem utilizados, antes mesmo que 0 roteiro seja pensado; para o filme-carta a escolha do equipamento se impõe como uma questão, trazendo a vantagem de se poder utilizar qualquer câmera sem que com isso tenhamos um problema de acabamento, como normalmente acontece quando filmamos policiais sem maquinaria ou noturnas sem potentes refletores e lentes extremamente luminosas, por exemplo. Com filmecarta não há filme mal acabado, pelo menos não por carências técnicas, o que é libertador quando estamos em oficinas ou no início de um curso de cinema. Como escreveu belamente Isaac Pipano (2012, p. 28) em 12 etapas e uma lição para se fazer um filme carta (em tempos de whatsapp), depois de escrever a carta, "pegue uma câmera (leia em voz alta e confira se há alguns erros gramaticais. Caso os encontre, mantenhaos. Se não houver, invente alguns: ninguém confia numa carta sem erros, escrita assim tão verdadeiramente sem rasuras)".

0 segundo aspecto nos ensina que a necessária reflexão sobre as máquinas tecnológicas facilita uma relação destas com os componentes sociais das tecnologias e os modos como os processos subjetivos estão a elas atrelados. Sobre este aspecto, podemos traçar uma linha entre a máquina e a influência que os escritos de Gilbert Simondon tiveram em Deleuze e Guattari. Segundo Simondon (2012, p. 327), “... é o trabalho que dá sentido aos objetos técnicos, não o objeto técnico que dá sentido ao trabalho", essa afirmação implica em uma forte politização dos objetos técnicos como atores moduláveis na máquinacinema. Uma modulação que é diretamente ligada à perfeição das máquinas - quanto mais indeterminação, mais perfeição. Ainda na introdução de Do modo de existência dos objetos técnicos, Simondon nos lembra da necessidade mesmo da existência desses objetos não estar separada dos devires humanos. E é relevante que 
este seja o mesmo filósofo que dedicou-se a pensar a educação e a horizontalidade das relações no espaço pedagógico, marcando, à seu modo, o fim da era disciplinar. Em um texto dos anos 800 autor coloca 0 seguinte:

0 século XIX teve que construir em algumas décadas uma sociedade de especialistas, adaptados à era da termodinâmica, segundo o princípio de rigidez: gerando um reforço da estrutura vertical, tornando-se onipresente e se estendendo mesmo onde antes havia estruturas horizontais. Nós devemos agora fazer em alguns anos uma educação que transforme a sobrevivência das relações verticais em relações horizontais. (SIMONDON, 1954, p. 83 tradução nossa)

Pois é nessa horizontalidade das relações com a tecnologia, também, que as estratégias do filmecarta podem nos ajudar. Estratégias que pela invenção refazem as relações homem/máquina.

Se a máquina nos fala de uma relação entre tecnologias e processos subjetivos, aproximemonos da escritura filmica propriamente. Em uma conferência feita em 1990 e publicada no livro Que est-ce que c'est l'ecosophie?, com o título, À propos des machines, Guattari marca uma distinção entre a noção de máquina e as análises semiológicas significantes dizendo que estas últimas trabalham dentro de uma "... linearidade que controla a totalidade das linhas de expressão" (GUATTARI, 2013 p. 123) para falar de máquinas, ele dá o exemplo do cinema.

No cinema, por exemplo, nós temos linhas de expressão: a linha sonora, a linha visual, a linha da cor. Não podemos falar de sintaxe ou de uma chave que tornaria homogênea as relações entre as diferentes linhas. Só existe um certo paraIelismo (GUATTARI, 2013 p. 123, tradução nossa).

A ausência de linearidade nos processos semiológicos pode até ser constituinte da imagem cinematográfica, mas, certamente, há toda uma história do cinema em que a construção dos filmes se faz por essa linearidade e homogeneização das imagens mesmas no interior da obra. A experiência-maquínica recoloca os estudantes em contato com as montagens semiológicas que operam uma produção de sentidos no respeito às potências significantes entre cada uma das linhas constituintes do cinema e seus acoplamentos, seus paralelismos. Para isso, o filme-carta, fortemente associado ao ensaio, parte do diálogo entre dimensões subjetivas e objetivas da imagem, da reflexividade intrínseca à carta, demandando uma relação direta dos cineastas com as imagens, além da liberdade de lidar com materiais heterogêneos e incorporar fluxos de imagens e consciência.

Se 0 cinema produz uma imagem discrepante em relação ao mundo filmado em que ela é sempre mais ou menos que a realidade, qualquer adequação ideal entre filme e realidade é uma violência. Esse, que é princípio da imagem mesmo, não é uma evidência; somos frequentemente assombrados por proibições em representar isso ou aquilo ou por imagens que se colocam no lugar de substitutas do real. Há uma construção propriamente pedagógica no filme-carta que coloca os estudantes imediatamente no desafio de um lugar parcial 
ante à realidade. Assim como qualquer estilo ou movimento, todo filme é uma forma de olhar e construir o mundo, se isso é uma evidência, precisamos de instrumentos para o trabalho e 0 filme-carta nos aproxima de uma multiplicidade de possibilidades e decisões de realização que aproximam os estudantes da singularidade da imagem e da necessidade de um ponto de vista, de um recorte e de uma montagem do mundo.

Comentando a montagem de Bertold Brecht em seus Jornais de Trabalho (1938-1955), DidiHuberman (2009, p. 60, tradução nossa) coloca de outra forma a dimensão maquínica constituinte das imagens e da própria história:

[...] 0 que há 'atrás' de uma acontecimento factual não é propriamente um 'fundo' insondável, uma 'raiz', uma 'fonte' obscura de onde a história tira toda a sua aparência. 0 que há 'atrás' é uma 'rede de relações', à saber, um prolongamento virtual que demanda do observador, simplesmente - mas não há nada simples nessa tarefa - multiplicar heuristicamente seus pontos de vista.

Tal multiplicação de pontos de vista em relação a um evento é 0 esforço que também faz Michel Foucault (1995 p. 135) quando nos diz que um enunciado está "sempre em déficit" e que "relativamente poucas coisas são ditas". Nas abordagens históricas que forjamos quando às relacionamos com a criação, como é 0 caso das disciplinas práticas em uma escola de cinema, uma parte fundamental é não fazer da história do cinema a raiz ou a gênese do que se produz hoje, nem, tampouco, uma história verborrágica, explícita e organizada. 0 filmecarta - uma forma de ensaio fílmico - racha qualquer unidade histórica autorizando o que poderíamos chamar de um nomadismo histórico que, na dispersão construtiva, traz da história do cinema os fragmentos que podem ludicamente trabalhar como atores tão singulares quanto a tecnologia, os blocos sonoros, os blocos textuais. Na maquinária histórica só há significação no movimento e na montagem. As consequências de tal abordagem colocam as produções dos alunos fora de um pertencimento histórico; ao mesmo tempo, passa a fazer parte de qualquer exercício com um filme-carta, a introdução da história do cinema na máquina pedagógica. Ou seja, não se trata de negar a história do cinema mas de desnaturalizar a sua harmonia e fazer com que cada filme faça parte de um devir-histórico. Não obstante, poderíamos convocar a tradição do filme-carta, uma tradição que se constitui com fragilidade e heterogeneidade, com realizadores como Chris Marker (Lettre de Sibérie, 1957), Jonas Mekas (Correspondance Mekas/JL Guerin, 2011), Abbas Kiarostami (Victor Erice / Abbas

Kiarostami. Correspondances, 2007), Agnes Varda (Ulysees, 1982), Jean Luc Godard (Letter to Jane, 1972), Chantal Akerman (News from Home, 1977), Eric Pawels (Carta de um cineasta a sua filha, 2000), Robert Kramer (Dear Doc, 1991), David Perlov (Diary, 1973 - 1983). Em suas diferenças, os filmes e realizadores acima, com seus ensaios e filmes-carta, permitem mobilizar elementos centrais nos estudos e no desafio do cinema: a atuação, o off, o campo/fora de campo, 
o visível/não visível articulados pela montagem e pelo quadro; as velocidades - cronológicas ou não-mensuráveis; a narrativa e as progressões, 0 estranhamento e a reflexividade, a suspensão, 0 distanciamento; a relação com o outro.

\subsection{Inventar um espectador}

Quando Jean Luc Godard é convidado por Michel Piccoli a fazer um filme sobre os 100 anos de cinema, a prática reflexiva do cineasta devolve a pergunta ao organizador das comemorações perguntando o que, exatamente, nós comemoramos? Comemoramos a primeira sessão paga, responde Piccoli (1995) em $2 X 50$. Na resposta de Piccoli, os filmes universitários ou feitos em escolas não são cinema; compartilham o dispositivo, mas não tem um público pagante. Certamente que levamos a lógica de Piccoli bastante longe, entretanto, esse é um dos desafios para o cinema feito em espaços educacionais. Como inventar um público? De maneira completamente distinta da noção cara ao marketing e à publicidade, não se trata de pensar um público-alvo. Nas artes, o público é inventado na própria obra, ele não preexiste como um consumidor que deve ser atendido. No caso do filme-carta esse público é dobrado, trazendo novos desafios para os estudantes. Por uma lado elegese um destinatário - a mãe, 0 amigo, o mundo construindo uma relação dual; aquele que escreve e aquele que recebe a carta. Por outro, não há apenas dois: é de um filme que se trata e este será visto em grupo, no cinema eventualmente.
0 filme-carta traz assim um fio estendido que vai do realizador ao destinatário, mas que ao chegar ao destinatário já chega rachado, aberto a uma multiplicidade de destinatários que 0 cinema virtualmente possui. Essa linha rachada é parte de uma máquina cinema que opera na fragilidade do gesto da carta, como um cinema menor, e, ao mesmo tempo, na busca do espectador qualquer - potência de afetação cara às artes. 0 filme-carta possui assim um aspecto relevante nos desafios do ensino: sem espectador não ficamos, ele existe, mesmo virtualmente, mesmo que a carta nunca seja aberta. 0 estudante tem assim um triplo desafio na relação de seu filme com os espectadores: 1) eles precisam inventar um espectador - não modelo; 2) precisam estar à altura desse espectador; 3) precisam estar preparados para o espectador qualquer, aquele que vai à sala de cinema e que faz rachar a linha reta entre destinatário e remetente.

\section{0 espectador não é assim o outro dos} realizadores, mas uma presença em todo 0 processo. No filme-carta essa presença do espectador é inalienável do seu fazer, o que frequentemente traz um engajamento mais intenso dos estudantes com as imagens produzidas. Não se trata apenas de um exercício, mas de uma relação direta de um sujeito, de um grupo, com um outro. Mas, esses desafios não cabem apenas aos realizadores, mas aos próprios espectadores, colocados para receber ou compartilhar a carta do outro. Singular trabalho, os filmes-carta demandam 
de seu público. Um trabalho que os coloca como espectador desafetado, aquele que pode, quando quiser deixar a sala, mas, simultaneamente, como destinatário ou espectador de uma correspondência que não lhe é dirigida - em ambos os casos, é um engajamento com as imagens que o filme convoca.

\section{Desdobramentos}

Este artigo foi fortemente mobilizado por duas práticas. Uma disciplina de Oficina de Realização Cinematográfica, realizada na Bacharelado em Cinema na Universidade Federal Fluminense e o trabalho ligado ao Inventar com a Diferença, projeto de cinema, educação e direitos humanos em mais de 250 escolas em todos os estados do país, coordenado pelo Departamento de Cinema da mesma universidade e ligado às pesquisas do Kumã: laboratório de Pesquisa e Experimentação em imagem e som. No primeiro caso a experiência criou um engajamento singular dos alunos, que tentei tecer nesse artigo, e cinco dos filmes produzidos em sala participaram da Mostra Filmes-carta - por uma estética do encontro. ${ }^{3}$ Um novo artigo mais dedicado na relação entre essas obras e a sala de aula seria possível. No segundo caso, um material de apoio pedagógico destinado a professores de ensino fundamental e médio foi produzido, tendo um filme-carta como proposta final. ${ }^{4} 0$ projeto se encontra em andamento, mas foi fortemente inspirado nas reflexões presentes neste artigo. ${ }^{5}$

\section{Referências}

BLANCHOT, M. 0 espaço literário. Rio de Janeiro: Rocco, 1987.

CLASTRES, P. A sociedade contra o Estado.

São Paulo: Cosac Naify, 2012.

COMOLLI, J. Ver e poder. A inocência perdida: cinema, televisão, ficção, documentário. Belo Horizonte: Editora da UFMG, 2008.

DELEUZE, G. Imagem-tempo. São Paulo:

Brasiliense, 2005.

DELEUZE, G. A imagem-movimento. São Paulo: Brasiliense, 1983.

DELEUZE, G. 0 Anti-édipo. São Paulo: Ed. 34, 2011.

DELEUZE, G.; GUATTARI, F. Mil platôs: capitalismo e esquizofrenia. São Paulo: Ed. 34, 1997. v. 5.

DIDI-HUBERMAN, G. Quand les images prennent

position. L'Oeil de l'histoire 1, Paris: Ed. De Minuit, 2009.

A Mostra foi organizada por Rúbia Mércia Medeiros (2012), a partir de sua dissertação Partida, Deslocamento e Exílio: escrever com a imagem o processo de subjetivação e estética em filmes-carta. Site da Mostra: http://www.mostradefilmescarta.com/ (última consulta em 9 jan. 2014)

Material de apoio pedagógico: http://www.inventarcomadiferenca.org/sites/default/files/Inventar_com_a_Diferenca_UFF_web.pdf 0 link para uma parte do material audiovisual que acompanha o projeto: http://vimeo.com/inventarcomadiferenca (última consulta em 9.1.2014)

Agradeço a Adriana Fresquet (UFRJ) e Isaac Pipano (UFF) pelas atentas e delicadas leituras e contribuições para este artigo. 
FEYERABEND, P. Contra o método. São Paulo: Editora Unesp, 2007

FOUCAULT, M. Arqueologia do saber. Rio de Janeiro: Forense Universitária, 2008.

GUATTARI, F. Qu'est ce que l'écosophie ?. Paris: Nouvelles Éditions Lignes, 2013.

GUATTARI, F. Lignes de fuite: pour un autre monde de possibles. Paris: Éd. de l'Aube, 2011.

LINS, C. Dear Doc: 0 documentário entre a carta e 0 ensaio fílmico. Devires - Revista de Cinema e Humanidades. Belo Horizonte: UFMG, 2006.

MEDEIROS, R. M. O. De Partida, deslocamento e exílio: escrever com a imagem o processo de subjetivação e estética em filmes-carta. 2012. 171p. . Dissertação ( Mestrado em Comunicação - Escola de Comunicação. Universidade Federal do Rio de Janeiro, 2012. Orientadora: Consuelo Lins.

PIPANO, I. 12 etapas e uma lição para se fazer um filme-carta (em tempos de whatsaap). In: MOSTRA FILMES-CARTA POR UMA ESTÉTICA DO ENCONTRO, Catálogo, MEDEIROS, Rúbia Mércia Oliveira (org.), Rio de Janeiro: Caixa Cultural, 2013. p. 28-29.

RANCIÈRE, J. A partilha do sensível: estética e política. São Paulo: Editora 34, 2005.

RANCIÈRE, J. A noite dos proletários: arquivos do sonho operário. São Paulo: Companhia das Letras. 1988.

RANCIÈRE, J. 0 Desentendimento: política e filosofia. São Paulo: Editora 34, 1996.

RANCIÈRE, J. La méthode de l'égalité: entretien avec Laurent Jeanpierre et Dork Zabanyan. Paris: Bayard, 2012

RANCIÈRE, J. 0 mestre ignorante: cinco lições sobre a emancipação intelectual. Belo Horizonte: Autêntica, 2007.

SERRES, M. Les cinq sens. Paris: Grasset, 1985.
SIMONDON, G. Réflexions préalables à une refonte de l'enseignement. Paris: Cahiers pédagogiques, 1954. SIMONDON, G. Du mode d'existence des objets techniques. Paris: Aubier, 2012.

WHITE, K. L'esprit nomade. Paris: B. Grasset, 1987. 


\section{The teaching of cinema and the} experience of the film-letter

\section{El enseno de cine y la experiencia de la película-carta}

\section{Abstract}

In this article I reflect on the commitments in the classroom in which the practice of cinema is central. I work the specific experience of the filmletter. To think the pedagogical space, I discuss the notions of emancipation (Jacques Rancière) and machine (Felix Guattari) trying to understand the role of film in education. The article also establishes a dialogue between Jacques Rancière and Gilles Deleuze / Félix Guattari's writing's, that despite their different philosophical backgrounds, they help us thinking the political dimension we bring to the teaching and practice of cinema.

\section{Keywords}

Cinema. Education. Film-letter. Emancipation. Machine.

\section{Resumen}

En este artículo reflexiono sobre los compromisos en el aula en que la práctica del cine es central. Trabajo una experiencia específica que es la película-carta. Para pensar el espacio pedagógico, discuto las nociones de emancipación (Jacques Rancière) y de máquina (Félix Guattari) tratando de entender cuál es el papel mismo del cine en la educación. El artículo también establece un diálogo entre dos filósofos franceses Jacques Rancière y los escritos de Gilles Deleuze y Félix Guattari que, aunque tienen diferencias filosóficas de fondo, nos ayudan a pensar en la dimensión política que aportamos a la enseñanza y práctica del cine.

\section{Palabras-Clave}

Cine. Educación. Película-carta. Emancipación. Máquina. 


\section{Expediente}

A revista E-Compós é a publicação científica em formato eletrônico da Associação Nacional dos Programas de Pós-Graduação em Comunicação (Compós). Lançada em 2004, tem como principal finalidade difundir a produção acadêmica de pesquisadores da área de Comunicação, inseridos em instituições do Brasil e do exterior.

\section{E-COMPÓS I www.e-compos.org.br I E-ISSN 1808-2599}

Revista da Associação Nacional dos Programas

de Pós-Graduação em Comunicacão.

Brasília, v.17, n.1, jan./abri. 2014.

A identificação das edições, a partir de 2008

passa a ser volume anual com três números.

\section{CONSELHO EDITORIAL}

Afonso Albuquerque, Universidade Federal Fluminense, Brasil Alberto Carlos Augusto Klein, Universidade Estadual de Londrina, Brasil Alex Fernando Teixeira Primo, Universidade Federal do Rio Grande do Sul, Brasil Ana Carolina Damboriarena Escosteguy, Pontifícia Universidade Católica do Rio Grande do Sul, Brasi

Ana Gruszynski, Universidade Federal do Rio Grande do Sul, Brasil Ana Silvia Lopes Davi Médola, Universidade Estadual Paulista, Brasil André Luiz Martins Lemos, Universidade Federal da Bahia, Brasi Ângela Freire Prysthon, Universidade Federal de Pernambuco, Brasil Antônio Fausto Neto, Universidade do Vale do Rio dos Sinos, Brasil Antonio Carlos Hohlfeldt, Pontifícia Universidade Católica do Rio Grande do Sul, Brasil Antonio Roberto Chiachiri Filho, Faculdade Cásper Líbero, Brasi Arlindo Ribeiro Machado, Universidade de São Paulo, Brasil Arthur Autran Franco de Sá Neto, Universidade Federal de São Carlos, Brasil Benjamim Picado, Universidade Federal Fluminense, Brasil César Geraldo Guimarães, Universidade Federal de Minas Gerais, Brasil Cristiane Freitas Gutfreind, Pontifícia Universidade Católica do Rio Grande do Sul, Brasil Denilson Lopes, Universidade Federal do Rio de Janeiro, Brasil Denize Correa Araujo, Universidade Tuiuti do Paraná, Brasi Edilson Cazeloto, Universidade Paulista , Brasil

Eduardo Vicente, Universidade de São Paulo, Brasil Eneus Trindade, Universidade de São Paulo, Brasil Erick Felinto de Oliveira, Universidade do Estado do Rio de Janeiro, Brasi Florence Dravet, Universidade Católica de Brasília, Brasil Gelson Santana, Universidade Anhembi/Morumbi, Brasi Gilson Vieira Monteiro, Universidade Federal do Amazonas, Brasil Gislene da Silva, Universidade Federal de Santa Catarina, Brasil Guillermo Orozco Gómez, Universidad de Guadalajara Gustavo Daudt Fischer, Universidade do Vale do Rio dos Sinos, Brasil Hector Ospina, Universidad de Manizales, Colômbia Herom Vargas, Universidade Municipal de São Caetano do Sul, Brasil Ieda Tucherman, Universidade Federal do Rio de Janeiro, Brasil Inês Vitorino, Universidade Federal do Ceará, Brasil Janice Caiafa, Universidade Federal do Rio de Janeiro, Brasil Jay David Bolter, Georgia Institute of Technology Jeder Silveira Janotti Junior, Universidade Federal de Pernambuco, Brasi João Freire Filho, Universidade Federal do Rio de Janeiro, Brasil John DH Downing, University of Texas at Austin, Estados Unidos
José Afonso da Silva Junior, Universidade Federal de Pernambuco, Brasil José Carlos Rodrigues, Pontifícia Universidade Católica do Rio de Janeiro, Brasil José Luiz Aidar Prado, Pontifícia Universidade Católica de São Paulo, Brasil José Luiz Warren Jardim Gomes Braga, Universidade do Vale do Rio dos Sinos, Brasil Juremir Machado da Silva, Pontifícia Universidade Católica do Rio Grande do Sul, Brasil Laan Mendes Barros, Universidade Metodista de São Paulo, Brasil Lance Strate, Fordham University, USA, Estados Unidos Lorraine Leu, University of Bristol, Grã-Bretanha Lucia Leão, Pontifícia Universidade Católica de São Paulo, Brasil Luciana Panke, Universidade Federal do Paraná, Brasil Luiz Claudio Martino, Universidade de Brasília, Brasil Malena Segura Contrera, Universidade Paulista, Brasil Márcio de Vasconcellos Serelle, Pontifícia Universidade Católica de Minas Gerais, Brasil Maria Aparecida Baccega, Universidade de São Paulo e Escola Superior de Propaganda e Marketing, Brasil Maria das Graças Pinto Coelho, Universidade Federal do Rio Grande do Norte, Brasil Maria Immacolata Vassallo de Lopes, Universidade de São Paulo, Brasil Maria Luiza Martins de Mendonça, Universidade Federal de Goiás, Brasil Mauro de Souza Ventura, Universidade Estadual Paulista, Brasil Mauro Pereira Porto, Tulane University, Estados Unidos Nilda Aparecida Jacks, Universidade Federal do Rio Grande do Sul, Brasil Paulo Roberto Gibaldi Vaz, Universidade Federal do Rio de Janeiro, Brasil Potiguara Mendes Silveira Jr, Universidade Federal de Juiz de Fora, Brasil Renato Cordeiro Gomes, Pontifícia Universidade Católica do Rio de Janeiro, Brasil Robert K Logan, University of Toronto, Canadá

Ronaldo George Helal, Universidade do Estado do Rio de Janeiro, Brasil Rosana de Lima Soares, Universidade de São Paulo, Brasil Rose Melo Rocha, Escola Superior de Propaganda e Marketing, Brasil Rossana Reguillo, Instituto de Estudos Superiores do Ocidente, Mexico Rousiley Celi Moreira Maia, Universidade Federal de Minas Gerais, Brasi Sebastião Carlos de Morais Squirra, Universidade Metodista de São Paulo, Brasil Sebastião Guilherme Albano da Costa, Universidade Federal do Rio Grande do Norte, Brasil

Simone Maria Andrade Pereira de Sá, Universidade Federal Fluminense, Brasi Tiago Quiroga Fausto Neto, Universidade de Brasília, Brasil Suzete Venturelli, Universidade de Brasília, Brasil Valerio Fuenzalida Fernández, Puc-Chile, Chile Veneza Mayora Ronsini, Universidade Federal de Santa Maria, Brasil Vera Regina Veiga França, Universidade Federal de Minas Gerais, Brasil

\section{COMISSÃO EDITORIAL}

Cristiane Freitas Gutfreind I Pontifícia Universidade Católica do Rio Grande do Sul, Brasil Irene Machado I Universidade de São Paulo, Brasil

Jorge Cardoso Filho I Universidade Federal do Reconcavo da Bahia, Brasil / Universidade Federal da Bahia, Brasil

CONSULTORES AD HOC

Adriana Amaral, Universidade do Vale do Rio dos Sinos, Brasil

Alexandre Rocha da Silva, Universidade Federal do Rio Grande do Sul, Brasi Arthur Ituassu, Pontifícia Universidade Católica do Rio de Janeiro, Brasil Bruno Souza Leal, Universidade Federal de Minas Gerais, Brasil Elizabeth Bastos Duarte, Universidade Federal de Santa Maria, Brasil Francisco Paulo Jamil Marques, Universidade Federal do Ceará, Brasi Maurício Lissovsky, Universidade Federal do Rio de Janeiro, Brasil Suzana Kilpp, Universidade do Vale do Rio dos Sinos, Brasil Vander Casaqui, Escola Superior de Propaganda e Marketing, Brasil

EDIÇÃO DE TEXTO E RESUMOS I Susane Barros SECRETÁRIA EXECUTIVA I Helena Stigger EDITORAÇÃo ELETRÔNICA I Roka Estúdio
COMPÓS I www.compos.org.br

Associação Nacional dos Programas de Pós-Graduação em Comunicação

Presidente

Eduardo Morettin

Universidade de São Paulo, Brasil

eduardomorettin@usp.br

Vice-presidente

Inês Vitorino

Universidade Federal do Ceará, Brasil

ines@ufc.br

Secretária-Geral

Gislene da Silva

Universidade Federal de Santa Catarina, Brasil

gislenedasilva@gmail.com 